\title{
Field analysis of solar PV-based collective systems for rural electrification
}

\author{
P. Díaz ${ }^{\mathrm{a}, *}$, R. Peña ${ }^{\mathrm{a}}$, J. Muñoz ${ }^{\mathrm{b}, 1}$, C.A. Arias $^{\mathrm{c}}$, D. Sandoval ${ }^{\mathrm{c}}$ \\ ${ }^{a}$ Escuela Politécnica, Universidad de Alcalâ, Campus Universitario, 28805 Alcalâ de Henares, Madrid, Spain \\ ${ }^{b}$ Grupo de Sistemas Fotovoltaicos, Instituto de Energía Solar, Universidad Politécnica de Madrid, Ciudad Universitaria, 28040 Madrid, Spain \\ ${ }^{\mathrm{c}}$ Empresa Jujeña de Servicios Energéticos Dispersos (EJSEDSA), Independencia 60, 4600 San Salvador de Jujuy, Jujuy, Argentina ${ }^{2}$
}

\section{A R T I C L E I N F O}

Keywords:

Solar photovoltaics

Hybrid

Rural electrification

\begin{abstract}
A B S T R A C T
This article analyses the long-term performance of collective off-grid photovoltaic (PV) systems in rural areas. The use of collective PV systems for the electrification of small medium-size villages in developing countries has increased in the recent years. They are basically set up as stand-alone installations (diesel hybrid or pure PV) with no connection with other electrical grids. Their particular conditions (isolated) and usual installation places (far from commercial/industrial centers) require an autonomous and reliable technology. Different but related factors affect their performance and the energy supply; some of them are strictly technical but others depend on external issues like the solar energy resource and users' energy and power consumption. The work presented is based on field operation of twelve collective PV installations supplying the electricity to off-grid villages located in the province of Jujuy, Argentina. Five of them have PV generators as unique power source while other seven include the support of diesel groups. Load demand evolution, energy productivity and fuel consumption are analyzed. Besides, energy generation strategies (PV/diesel) are also discussed.
\end{abstract}

\section{Introduction to PV and PV-diesel collective microgrids}

Electricity is supplied throughout the world primarily through interconnected distribution networks. However, there are still many places where the grid does not reach. Low population density, low energy demand (low incomes) and underinvestment in infrastructures are behind that situation. International agencies report that 1.5 billion people [1] have no access to electricity, which is more than $20 \%$ of world's population. Electrification rates differ between the rural environment (63.5\%) and the urban world (more than $93 \%$ ). Electrifying low-density rural regions, mainly located in developing countries, is not feasible in pure economical terms. Other motivations, like social equity and rural development should stimulate present and future sustainable rural electrification plans and funding programmes, with public and private agents [2].

Although power transmission grids are progressively spreading to new areas within the regional or national electrification plans, many places will remain out of their influence at least during the next decades. Alternative technologies are being used to supply electricity to those dispersed areas, like small thermal diesel groups, biomass generators, solar photovoltaic systems, small wind and micro-hydro turbines.

Thermal generation is the most widespread technology for offgrid electrification. However, its dependency on fuel supply, its high operational costs (mainly due to fuel spent and systems maintenance) and, recently, the environmental concerns have enhanced the introduction of renewable energies. Obviously, the availability of the renewable energy resource at the local level is the first condition for their implementation. The analysis of existing data or on-site measurements is then required as a pre-installation step.

Together with well-known grid-connected applications, mainly promoted and installed in industrialised countries so far, off-grid photovoltaic systems (PV) constitute a suitable technology for rural electrification. A complete overview on PV decentralized rural electrification state-of-the art and emerging trends has been published by Chaurey [3].

Main advantages of PV technology come from its flexibility: system power range from a few watts to some kilowatts. Besides, system repowering can be done if energy demands increase, attending to some simple matching conditions.

off-grid photovoltaic systems are designed in two different configurations, depending on the number of clients attended and their closeness: single and collective installations. If single systems are used, each household has its own PV array, batteries and loads. However, for small medium village supply, it is more suitable to 


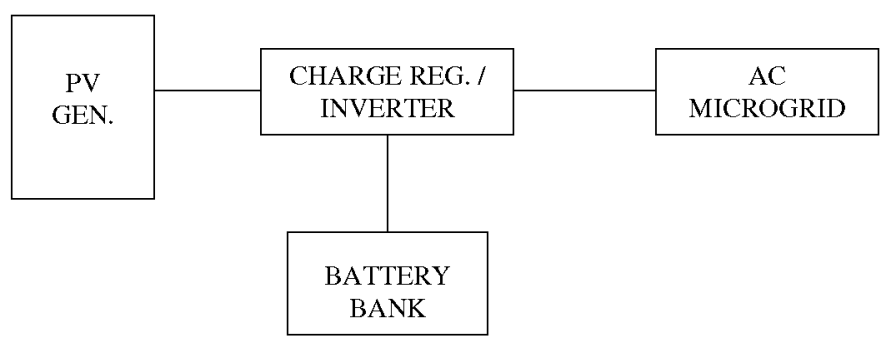

Fig. 1. Collective PV installation single-line diagram.

centralize the generation and storage in a collective system. Electricity is distributed by means of an $A C$ microgrid that is not connected to any external network. A comparative simulation study between individual systems and microgrid shows the influence of the number of households, their distance (grid length) and the load demand [4] on the optimum configuration.

A single-line diagram of these PV stand-alone systems is shown in Fig. 1.

Energy supply reliability can be increased by adding a diesel generator to the collective PV-battery system, in the so-called hybrid systems. The thermal generator is expected to work as a support, in the case of high power loads, a growth in demand or low solar radiation, although it can be used also for battery recharging. Otherwise, these hybrid systems can be seen as a practical improvement of common diesel generators, to reduce fuel consumption. Their single-line diagram is presented in Fig. 2.

Both types of collective PV systems, with or without diesel support, have experienced a significant growth in the last 10 years as a useful technology for the electrification of small villages in the rural world. Experiences coming from China [5], Morocco [6], Thailand [7] or Brazil [8] enhance the relevance of this technology. Although the energy provision to remote places is their main advantage, other studies like their energy-pay-back analysis [9] are also useful to advance in their knowledge.

Within this framework, this paper intends to contribute to the comprehension of collective off-grid PV systems performance in rural electrification from field information. First, a general discussion on the different control strategies to be applied to collective PV systems is introduced, mainly focused on hybrid PV-diesel ones. Then, a study on the operation of collective PV systems is presented, based on fieldwork in 12 sites in the province of Jujuy, northwest Argentina. In these villages are about 500 'clients', mainly families, but also schools, churches, community premises, etc. Five of the villages have pure PV installations, while the other seven include a diesel generator as a back-up. In all cases the electricity is distributed from the centralized generation system to the village by means of $A C$ microgrids. Electricity is mainly used for lighting, radio and some small TVs. There are some units of low power machinery but no thermal applications.

\section{Generation control strategies in collective PV systems}

Generation vs. consumption balance in PV-battery systems, with no additional support, has its limit on the regulation setpoints (state-of-charge or voltage) adjusted at the charge controller. It is a crucial factor when matching the battery-charge controller characteristics, since the electricity supply during bad weather or high consumption periods relies on it.

Once loads are switched-off due to low battery state, the adjustment of the load reconnection point is also important. It has to assure a sufficient battery recharge, together with a short-aspossible energy black-out. A $0.15-0.2 \mathrm{~V} /$ cell gap between load disconnection and reconnection is recommended [10] (1.8-2.4 in a $24 \mathrm{~V}$ system). The lower limit implies a sooner electricity supply restoration but still with a medium low battery state, while the upper one extends the time without supply for a better battery recharge. It is clear that the battery recharge and then, the duration of the black-out, depend on the incident solar radiation during the following hours or days.

Common problems of small individual installations rise in collective systems, since an over-consumption from one of the users can cause a global black-out in the village. In individual systems the own user can manage its energy demand, but in collective installations different energy control methods can be applied:

- Programmed supply schedule ( 8 h, 12 h, 18 h or full 24 h/day), only if there are no equipment with permanent electricity requirements connected to the microgrid. In this case an independent power supply should be used for them.

- Identification of primary load needs and secondary ones [11], with parallel electricity supply circuits, depending on the battery status.

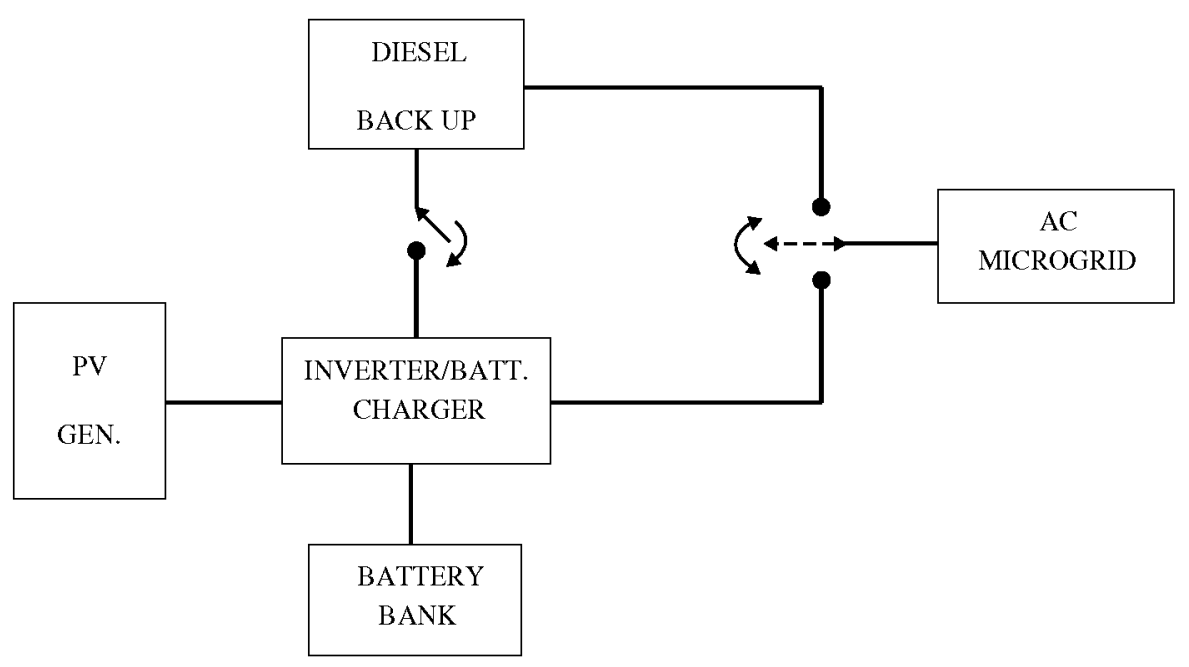

Fig. 2. Collective PV-diesel hybrid installation single-line diagram. 
- Together with common thermal magnetic (overcurrent) circuit breakers, include energy limiters at each consumption point.

- Establish a tariff system to prevent from over-consumption.

Compared to PV-battery systems, energy control strategies of PV-hybrid plants are at the same time more complex but also less critical: a deep-battery-discharge does not imply an electricity black-out, but an increase in fuel expenses. The strategy for diesel generator connection, operation and disconnection has to be defined.

Different strategies concerning PV/battery-diesel sequence for electricity generation and dispatch can be implemented in the field. Interesting works are found in literature on these issues, mainly based on the development of optimization methods to obtain the lower-cost design and dispatch strategy, like Barley [12], Seeling [13] or Gupta [14]with a deeper analysis of battery degradation, Muselli [15] analyzing the influence of load profile or Dufo-López [16] by using genetic algorithms. A complete bibliographic and software tools review on hybrid systems simulation and optimization has been presented by Bernal-Agustín [17].

Functional strategies of hybrid systems can be classified in two main groups according to the diesel generator operation. In all cases the PV-battery subsystem is suppose to work as main power supplier and the diesel one as support.

\subsection{Diesel with no battery-charger function}

In this group of systems, once the diesel generator starts its operation, it provides just the power demanded by the loads. No diesel power is used to recharge the batteries, then. Within this group, there are different options depending on the switching method: time-scheduled (manual or automatic) or triggered by battery state-of-charge (or voltage). It is a simple configuration, especially the manual switching used in old systems, that improves the electricity supply to the villages compared with PV systems with no other support. However, neither the diesel nor the PVbattery subsystems are optimised. First, as it was explained before, diesel generators decrease their efficiency at low power. If the load power requested is far from nominal values, which is common in rural electrification, fuel consumption rates strongly increase. Besides, batteries delay their reconnection time until there have been enough PV energy recharging.

\subsection{Diesel with battery-charger function}

In these cases, the diesel generator has a double function once it is in operation: supplying the load demanded by the village and recharging the batteries, if there is power surplus. The diesel generator installed should have enough power for both functions at least at a limited extent (charging current). Considering that diesel generators offer their best efficiency at nominal power, it seems reasonable to approach to it by adding a limited extra power for battery recharging. The benefits of this option depend on operating thresholds and on the load profile variability. In fact, the use of

Table 1

Settings for diesel generator auto-start and stop ( $24 \mathrm{~V}$ system).

\begin{tabular}{ll}
\hline & Inverter/charger settings \\
\hline Diesel start & $24 \mathrm{~h}$ below $24.6 \mathrm{~V}$ \\
& $2 \mathrm{~h}$ below $23.6 \mathrm{~V}$ \\
& 15 min below $22.6 \mathrm{~V}$ \\
& $30 \mathrm{~s}$ below $22.0 \mathrm{~V}$ \\
Diesel stop & $\mathrm{V}_{\text {float }}(26,8 \mathrm{~V})[+2 \mathrm{~h}]$ \\
\hline
\end{tabular}

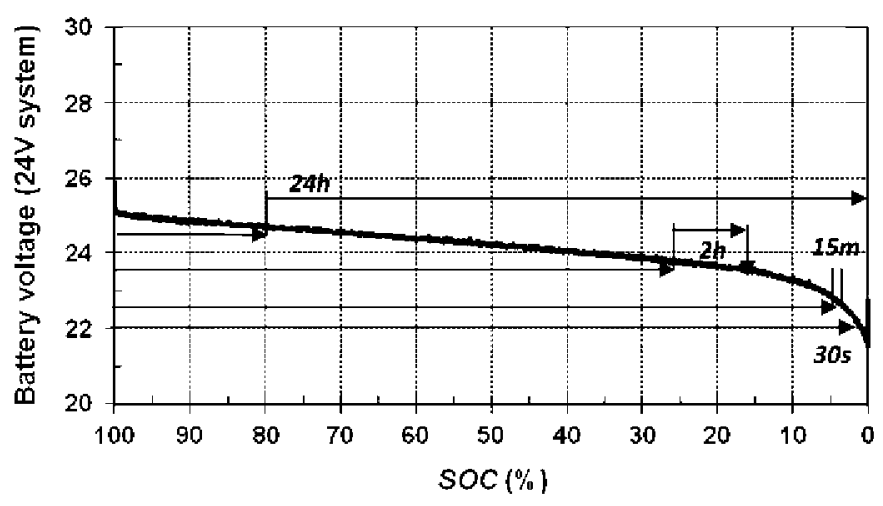

Fig. 3. Example of diesel group switching-on configuration, referred to a constant $I_{20}$ current battery discharge test ( $350 \mathrm{~A}$ h/24 V battery).

batteries is one of the existing options to shift the diesel generator to more efficient working conditions [18].

As an advance, the hybrid systems studied in this work, the default settings of the inverter/battery-charger used are shown in Table 1. In Fig. 3 they are put together with a laboratory constant current battery discharge curve, taken as an example. The diesel starts and stops automatically in pre-defined conditions, if batteries are able to supply again the required load demand.

It is expected that the 15 min and the 30 s settings will be only activated in case of high peak loads or strong aged batteries. The $2 \mathrm{~h}$ setting should be the switching-on point in normal operation, so it will mark the battery depth-of-discharge (around $80 \%$ in the laboratory curves, common for stationary batteries). The $24 \mathrm{~h}$ setting would be only activated if low power is demanded during a long period.

Attention is commonly paid to those end-of-battery-discharge points, but the definition of the diesel operation time/setups and the subsequent battery reconnection for load supply deserves more discussion.

In the studied systems, the diesel generator recharges the batteries at a limited $15 \mathrm{~A}$, until the floating voltage is reached, plus 2 more hours of recharge as an option. By applying this setup to a battery laboratory recharge line (Fig. 4) results a recharge up to $50 \%$ of battery stored energy. It is supposed than in the previous discharge at least $15-20 \%$ remains in the battery, so in fact the recharged energy is about $30-35 \%$ of battery capacity until the floating voltage is reached plus another $5-10 \%$ in the following $2 \mathrm{~h}$. The rest of the recharge should be supplied by the PV system.

Depending on the diesel generator working point and its efficiency, fuel expenses in each recharging cycle can be evaluated, considering around $0.4 \mathrm{l} / \mathrm{kW}$ h at full load.

This analysis does not pretend to establish definite operational rules, since there are as many particular situations as systems installed, but to contribute to advance in PV-hybrid systems field operation understanding. An interesting future work to be applied in the field consists on modifying these settings, in order to study the fuel consumption together with battery performance and the energy supply at different configurations.

In the following sections a detailed description of the systems is presented together with more relevant results of the performance evaluation work.

\section{System monitoring \& avalilable data}

The outcomes of a field evaluation analysis stand on the quality of the available information. Unfortunately it is usually not enough in rural electrification applications: a good evaluation plan, enough 


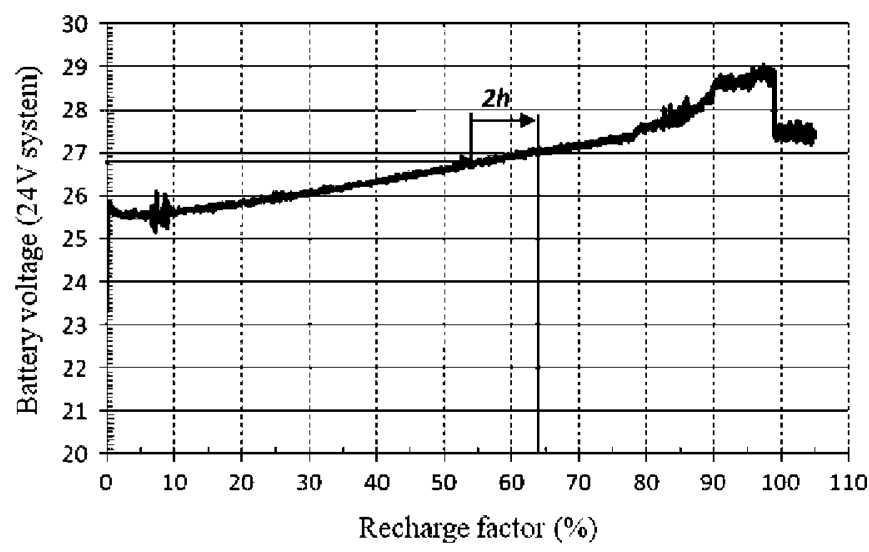

Fig. 4. Example of diesel group recharge configuration, referred to a constant $I_{24}$ current battery charge test ( $350 \mathrm{~A} \mathrm{~h} / 24 \mathrm{~V}$ battery).

money-investment and time are the necessary requirements. We are convinced that it would be recovered in a short time trough better systems operation, improved reliability, lower maintenance and replacement costs, lower fuel consumption and a more satisfactory energy service. We also think that field evaluation works are an unavoidable complement to pre-installation software simulations applied to particular geographical conditions in developing countries like Bangladesh [19], Malaysia [20], Cameroon[21], Saudi Arabia [22] Algeria [23] or Egypt [24]. Simulation works including wind energy [25] and hydro [26] have been also published. Due to the great complexity of PV rural electrification, from the technical and social points of view, lessons learned from the field have their own value.

With no question, it is more valuable to monitor an off-grid PV system during long periods (more than 5 years) even more when one of the components is a living and complex element (users) that permanently change their behavior, in energy demand terms. Besides, the aging effect on some equipment (i.e. batteries) has an enormous influence in the energy balance and supply. In the case study here presented, the evaluation period is 2001-2008.

The long-term study is based in the following information collected from the field:

- Name and location of each village

- Number of users (consumer units) per village

- Technical characteristics of the generation/storage systems

- Total electricity generation ( $\mathrm{kW} \mathrm{h/month)}$

- Fuel expenses (1/month)

Although the available information has a significant value for the present work, for future monitoring designs it would be very useful to register PV and diesel generation independently, in order to accurately evaluate the contribution of each system to the load demand and battery recharging. A deeper analysis would have required also some data about the number of diesel group starts due to low battery state-of-charge and the hourly load profile to detect peak loads.

\section{Performance evaluation of collective PV and PV-diesel systems}

\section{1. $P V$ and PV-diesel design analysis}

Any system performance evaluation should start with the appraisal of the initial design. Since an off-grid system is sized
Table 2

Design data of collective PV installations.

\begin{tabular}{|c|c|c|c|c|c|c|}
\hline Id & Location & $\begin{array}{l}\mathrm{N} \\
\text { households }\end{array}$ & $\begin{array}{l}\text { Nominal system } \\
\text { voltage }\left(\mathrm{V}_{\mathrm{DC}}\right)\end{array}$ & $\begin{array}{l}\text { PV gen } \\
(\mathrm{Wp})\end{array}$ & $\begin{array}{l}\text { Wp per } \\
\text { household }\end{array}$ & $\begin{array}{l}\text { Battery } \\
\operatorname{bank}(A h)\end{array}$ \\
\hline 1 & $\begin{array}{l}\text { El } \\
\text { Angosto }\end{array}$ & 19 & 48 & 2100 & 110 & 900 \\
\hline 2 & $\begin{array}{l}\text { La } \\
\text { Ciênaga }\end{array}$ & 23 & 48 & 3000 & 130 & 1200 \\
\hline 3 & $\begin{array}{l}\text { San } \\
\text { Francisco }\end{array}$ & 10 & 48 & 1800 & 180 & 900 \\
\hline 4 & $\begin{array}{l}\text { San Juan } \\
\text { y Oros }\end{array}$ & 19 & 48 & 2100 & 110 & 900 \\
\hline 5 & $\begin{array}{l}\text { Timón } \\
\text { Cruz }\end{array}$ & 13 & 48 & 1500 & 115 & 900 \\
\hline
\end{tabular}

according to the energy demand forecasts, first real consumption values should be checked and compared with the installation capabilities. Besides, the whole system, with its components, has to be well designed too. Different operational problems depend on systems design, mainly due to undersized installations.

Five villages electrified with centralized PV generators and AC distribution microgrids have been analyzed. They are small villages between 10 and 23 households. As it is obvious, there is no fuel consumption there. Basic design data are summarized in Table 2.

The DC side operates at nominal $48 \mathrm{~V}$ in all cases, with the PV array designed according to the village population, but also particular consumption forecasts and budget limitations. However, battery bank sizes were standardized in design. Hence, the ratio battery nominal power vs. PV array ranges from 19.2 to $28.8 \mathrm{~W} \mathrm{~h} /$ Wp, so different cycling regimes for the variety of generation and consumption profiles are expected. However, no significant longterm performance remarks have been detected due to this wide range of battery relative sizes.

Seven more villages were supplied with hybrid PV-diesel systems. These locations are more populated than the ones supplied by only-PV installations, ranging from 20 to almost 120 households. There are three $24 \mathrm{~V}_{D C}$ and four $48 \mathrm{~V}_{D C}$ systems, with PV arrays between $0.8 \mathrm{~kW}$ p up to more than $4.6 \mathrm{~kW}$ p. All $24 \mathrm{~V}_{D C}$ systems have the same battery bank size, $1200 \mathrm{~A}$ h, while in the 48 $\mathrm{V}_{\mathrm{DC}}$ ones the batteries are of different capacity. Main design data are summarized in Table 3. It can be observed that the PV power per household is lower than in the pure PV systems.

It should be noted also that all diesel generators are $17 \mathrm{kV} \mathrm{A}$ ones. Regarding that the number of households attended by each system is quite different from one place to another, diverse operational regimes are expected when these diesel groups are switched on. This point affects the diesel generator efficiency and so, the fuel expenses compared to their optimum performance.

Table 3

Design data of collective PV-diesel installations.

\begin{tabular}{|c|c|c|c|c|c|c|c|}
\hline Id. & Location & $\begin{array}{l}\mathrm{N} \\
\text { households }\end{array}$ & $\begin{array}{l}\text { Nominal } \\
\text { system voltage } \\
\left(\mathrm{V}_{\mathrm{DC}}\right)\end{array}$ & $\begin{array}{l}\text { PV } \\
\text { gen } \\
(\mathrm{W} p)\end{array}$ & $\begin{array}{l}\text { Wp per } \\
\text { household }\end{array}$ & $\begin{array}{l}\text { Battery } \\
\text { bank } \\
(\mathrm{A} \mathrm{h})\end{array}$ & $\begin{array}{l}\text { Diesel } \\
(\mathrm{kV} \mathrm{A})\end{array}$ \\
\hline 6 & Lagunillas & 63 & 48 & 2400 & 38 & 1080 & 17 \\
\hline 7 & $\begin{array}{l}\text { Loma } \\
\text { Blanca }\end{array}$ & 29 & 48 & 1060 & 36 & 900 & 17 \\
\hline 8 & Misarrumi & 38 & 24 & 844 & 22 & 1200 & 17 \\
\hline 9 & Orosmayo & 19 & 48 & 2100 & 110 & 900 & 17 \\
\hline & $\begin{array}{l}\text { Pastos } \\
\text { Chicos }\end{array}$ & 31 & 24 & 920 & 29 & 1200 & 17 \\
\hline & $\begin{array}{l}\text { Pozo } \\
\text { Colorado }\end{array}$ & 33 & 24 & 1062 & 32 & 1200 & 17 \\
\hline 12 & Santa Ana & 118 & 48 & 4664 & 39 & 3000 & 17 \\
\hline
\end{tabular}




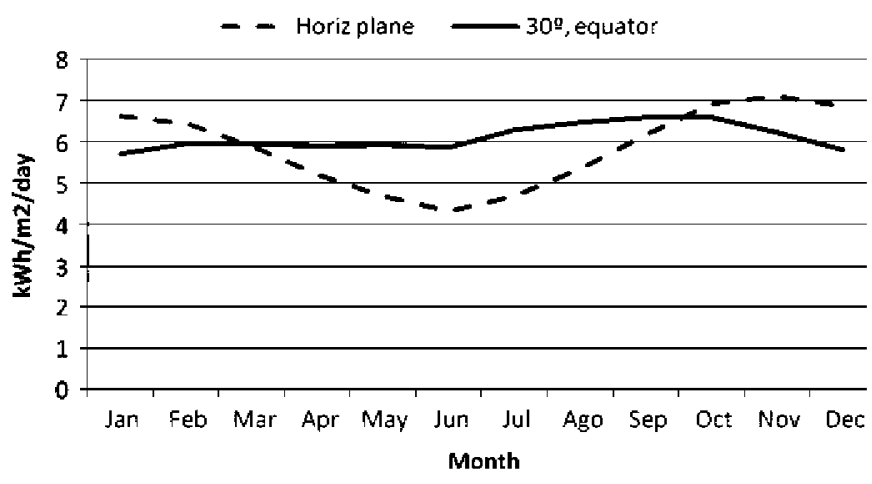

Fig. 5. Solar radiation data, La Quiaca, Jujuy, Argentina (Source: RETScreen).

Using RETScreen software or simple energy balance calculations, a rough estimation of the annual PV energy generation potential is obtained for the given systems. For design evaluation purposes, solar radiation data correspond to La Quiaca (22 ${ }^{\circ} 6^{\prime} \mathrm{S}, 65{ }^{\circ} 34^{\prime} \mathrm{W}$, 3400 m.s.l), bordering Argentina and Bolivia, which is close to the analyzed villages, with similar altitude and climate conditions. As it is shown in Fig. 5, the solar radiation profile for a $30^{\circ}$ tilted plane is quite constant throughout the year, with an annual mean value of $6.1 \mathrm{~kW} \mathrm{~h} / \mathrm{m}^{2}$ day. Temperatures are mild or even cold, due to the altitude, leading to good conditions for PV technology. However, the same high altitude reduces the diesel generator efficiency and increases its wear due to lower air density [27].

By comparing the PV generation estimates with first real data (year 2001), it is shown in Table 4 that none of the studied PV systems (id. 1-5) are undersized. Some of them were used fairly extensively while others were underutilized to some extent. In all of them there is enough margin thinking in possible demand growth and future component aging, mainly battery capacity loss.

Concerning PV-diesel systems, in most of the villages the PVbattery subsystem was not designed to supply the whole energy demand but to partially contribute to it. Field data confirm that appreciation, as shown in the same Table 4 (id. 6-12). Undersized and less costly PV systems should be supported by the diesel operation at different degrees. Besides, in all hybrid systems the thermal generator also switches on in case of high load peaks or low irradiation. As shown in the following sections, system design has direct consequences on fuel expenses, as expected.

\subsection{Electricity supply analysis}

After verifying the initial design a deeper analysis on energy demand supply is done. Apart from its influence on systems'

\section{Table 4}

Annual PV energy potential, $\mathrm{E}_{\text {est, }} \mathrm{PV}$ and total energy measured generation, $\mathrm{E}_{\mathrm{msr}}$ total (year 2001).

\begin{tabular}{llll}
\hline Id. & $\mathrm{E}_{\mathrm{est}, \mathrm{PV}}(\mathrm{MW}$ h/year $)$ & $\mathrm{E}_{\mathrm{msr}, \text { total }}(\mathrm{MW}$ h/year $)$ & $\mathrm{E}_{\mathrm{msr}, \text { total }} / \mathrm{E}_{\mathrm{est}, \mathrm{PV}}(\%)$ \\
\hline 1 & 3,79 & 2,69 & 71,0 \\
2 & 5,37 & 2,96 & 55,1 \\
3 & 3,27 & 1,98 & 60,6 \\
4 & 3,79 & 1,34 & 35,4 \\
5 & 2,75 & 1,34 & 48,8 \\
6 & 4,33 & 6,03 & 139,3 \\
7 & 1,98 & 2,04 & 102,8 \\
8 & 1,56 & 3,17 & 203,5 \\
9 & 3,77 & 1,92 & 50,8 \\
10 & 1,7 & 3,02 & 177,9 \\
11 & 1,94 & 2,79 & 144,0 \\
12 & 8,6 & 8,47 & 98,4 \\
\hline
\end{tabular}

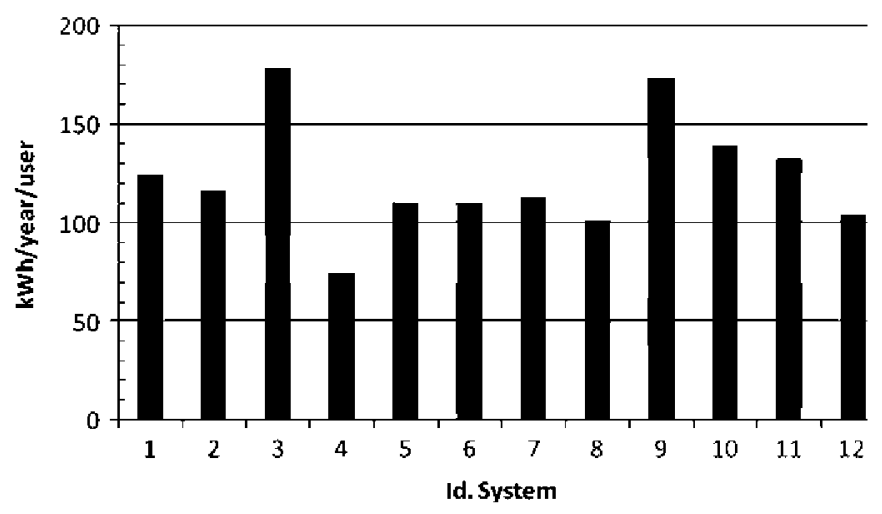

Fig. 6. Energy compsumption per year and household (8 years average values 2001-2008, system id. numbers as shown in Tables 2 and 3).

performance, learning from field consumption data is a significant value by itself.

In Fig. 6 yearly mean energy consumption values per user are shown for the twelve villages analyzed. Values around $120 \pm 15 \% \mathrm{~kW} \mathrm{~h} /$ year/household are a reference consumption pattern for these places ( $330 \mathrm{~W}$ h/day). In one of the villages (id. 4) consumption was considerable lower than that, although the system design was not the limiting factor. Besides, in two of the systems (id. 3 and 9), design load requirements per user were higher because of the presence of some small machinery.

In average, there is not a significant difference in total energy demand between the systems with diesel support and the ones that do not include any auxiliary supply. So, it is not the generation technology what constraints the users' energy demand but their own electrical equipment, family size and lifestyle.

However, it is interesting to analyze the evolution during the years of the energy supplied to the villages by each type of technology. Fig. 7 shows how in pure PV installations, the average energy demand has not changed significantly during the last 8 years. Component degradation, basically batteries, would lead to a reduction in energy disposal, but as it was shown before there was enough reserve in PV array and battery sizing.

On the contrary, in villages equipped with PV-diesel systems there has been a progressive energy demand increase. As the PV array was undersized in design, this growth has been met mainly by the diesel generators. Fuel consumption has almost doubled in 8 years. Then, systems tend to be more dependent on diesel fuel. In this situation, to recover the initial PV contribution a repowering is required so the fuel expenses can be again reduced.

Mean full tariffs in collective systems include a fixed charge of 39 US\$ per month plus a consumption charge of $0.47 \mathrm{US} \$ / \mathrm{kW} \mathrm{h}$

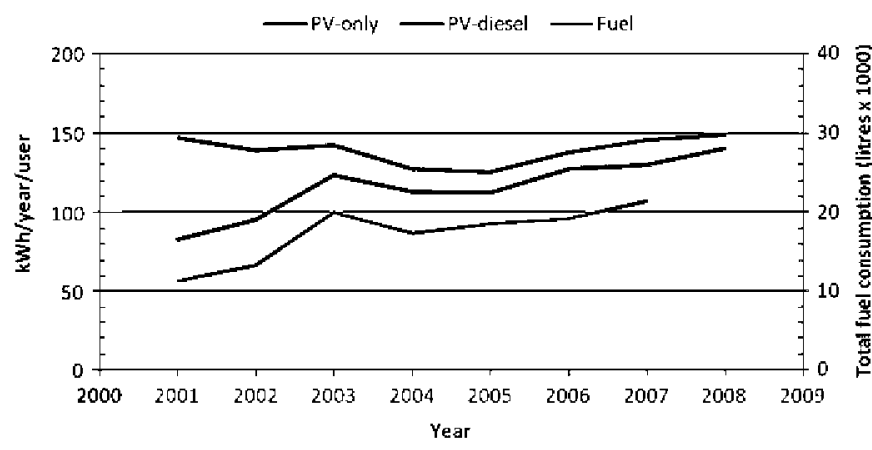

Fig. 7. Total annual energy generation and fuel consumption (of PV-diesel systems). 
consumed. Users pay about $10 \%$ of the total while the $90 \%$ is subsidized by the governmental institutions.

\subsection{Only-PV systems performance evaluation}

One of the determining parameters commonly used for gridconnected PV system evaluation is the productivity yield, defined as the generated energy, per year, normalized to nominal PV power $(\mathrm{kW} \mathrm{h} / \mathrm{kW} \mathrm{p}$ ). This factor includes the energy losses of the whole system but also the solar radiation received by the PV array.

In stand-alone systems the productivity yield is not so used as a system quality verifier, however, some interesting results can be outlined. Main difference stands in the demand influence: if load consumption is low, whatever the reason, batteries prone to overcharge. Then, the PV array generation is regulated or even interrupted to protect them and the productivity yield is reduced because of full energy stored. Considering this, the productivity yield in off-grid systems includes also the utilization level of the system, which is not a technical quality indicator but a valuable parameter for the evaluation of an electrification program. In Fig. 8 mean productivity yield values registered on PV systems are shown.

If the system sizing is done with realistic demand forecasts there should be no significant relation between the system productivity and the nominal PV array power. Values around or even above $1000 \mathrm{~kW} \mathrm{~h} / \mathrm{kW} \mathrm{p} /$ year are considered as very positive in off-grid systems with static structures, as they are the majority of them. They point out not only good technical conditions but also an optimum use of the system by the inhabitants.

Lower productivity values require a more datailed analysis. As it was explained, they can show bad technical quality conditions, like PV array shadowing or battery aging, but also an underutilized system. To distinguish between generation problems and low consumption, voltage values or number of load disconnections should be registered.

By following the productivity evolution during the years some hints on system performance appear. Results of two of the systems are presented in Fig. 9. In one of them, the installation initially perfomed at very good level, with no significant problems. During the years its productivity has been reduced, which is normal. If there has not been a decrease in the village population or per-capita energy demand, which is not expected, a progressive but slow system degradation has taken place, probably due to battery aging.

On the contrary, the other system had a wider growth margin from its initial size. Later on, its productivity rate has progressed at reasonable levels, which is a symptom of good technical

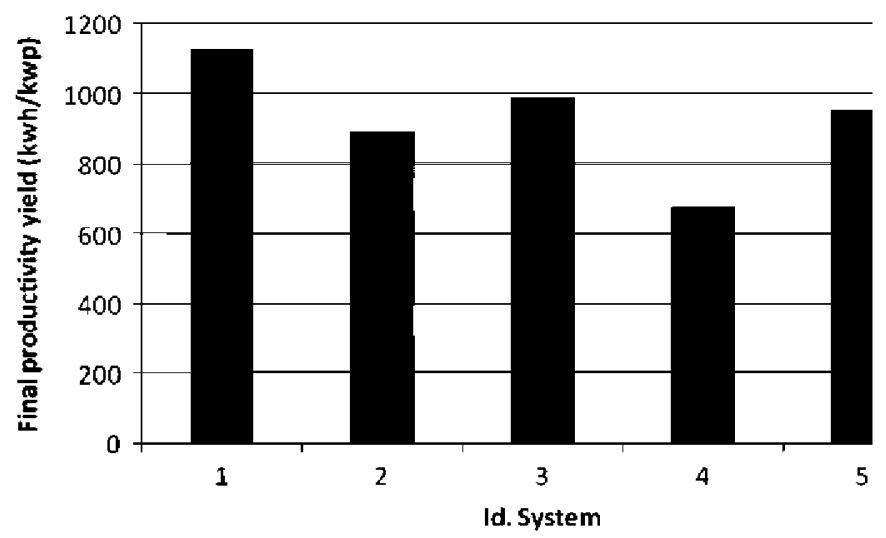

Fig. 8. PV system productivity yield (Collective PV installations, 8 years average values 2001-2008, system id. numbers as shown in Table 2).

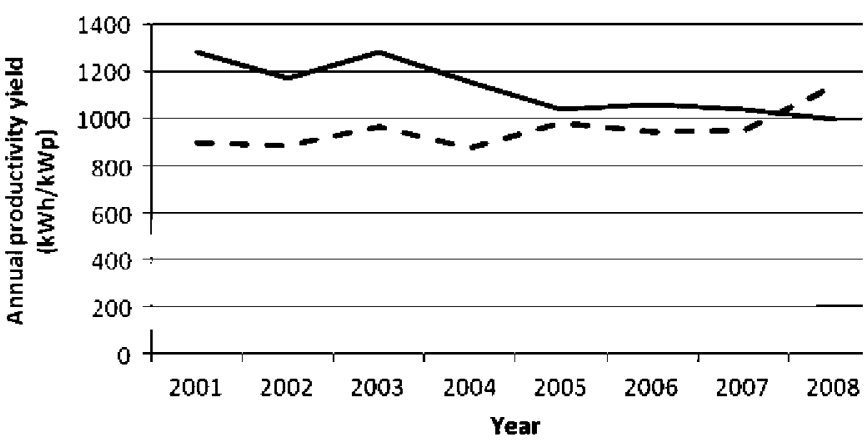

Fig. 9. System productivity evolution of two different PV installations (id. system 1solid line and 5-broken line, of Table 2).

performance and optimum balance between real generation potential and demand.

Going back again to Table 4 , it can be observed how system id. 1 had a higher use in the first stages than system id.5, which can explain further evolution.

\subsection{Hybrid PV-diesel systems performance evaluation}

The operation of hybrid PV-diesel systems is significantly different than pure PV ones. In hybrid installations, the energy demand that the PV-battery subsystem is not able to meet is supplied by the diesel generator, as explained before. But, of course, the aim of these systems is to maintain fuel expenses as low as possible. However, due to initial design values and subsequent load demand increases, diesel technology carries the most weight. Battery aging also drives the system in the same direction.

To hinder on this collaborative and flexible operation, fuel consumption values per $\mathrm{kW}$ h supplied to the villages are evaluated and shown in Table 5. These values should not be confused for diesel generator efficiencies. In the case studies here presented the fuel consumption values are related to the combined PV/ diesel production taken as a 'black-box', since the monitoring system was not designed to measure independent generation. Then, both generator efficiency and PV/diesel contribution are included.

In order to valuate the usefulness and feasibility of hybrid PVdiesel systems compared with traditional diesel generators, the desired fuel saving should be verified. At this point the reader has to be aware that fuel consumption values of diesel generators around $0.351 / \mathrm{kW} \mathrm{h}$, commonly referred in technical specfications correspond to larger generators working at their rated power. At $25 \%$ power, consumption can increase up to $0.61 / \mathrm{kW} \mathrm{h} \mathrm{[28],} \mathrm{and}$ even more in the case of small machines. Papadopoulos [29] has presented laboratory works on the influence of variable load profiles on the energy efficiency of diesel and hybrid PV-diesel systems.

Table 5

System fuel rate values per $\mathrm{kW}$ h ( 5 years average values 2003-2007, id. numbers as shown in Table 3).

\begin{tabular}{ll}
\hline Id. & System fuel rate $(1 / \mathrm{kW} \mathrm{h})$ \\
\hline 6 & 0,56 \\
7 & 0,38 \\
8 & 0,63 \\
9 & 0,32 \\
10 & 0,66 \\
11 & 0,63 \\
12 & 0,35 \\
\hline
\end{tabular}




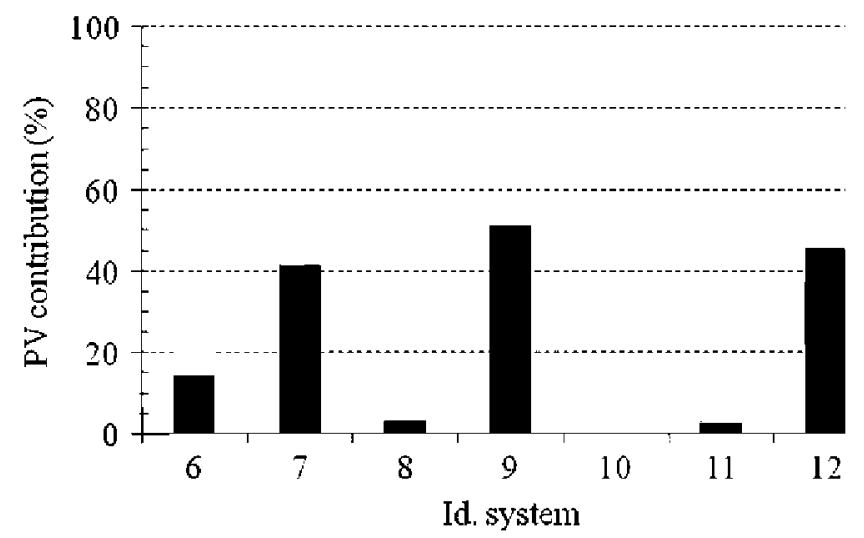

Fig. 10. PV contribution to global electricity generation of PV-diesel systems ( 5 years average values 2003-2007, id. numbers as shown in Table 3).

Field experiences on diesel systems at the same province of Jujuy show mean values around $0.7 \mathrm{l} / \mathrm{kW}$ h for low power gensets in low regime operation [30] and high altitudes above 3000 m.s.l. It should be noted that in rural electrification the demanded power during most of the day is lower than $25 \%$ of the peak power.

PV contribution to yearly electricity generation in hybrid systems has been estimated. Diesel generator efficiency values between 0.65 and to $0.75 \mathrm{l} / \mathrm{kW}$ h are taken as hypothesis, according to previous field experiences. Results are shown in Fig. 10. In three systems the contribution of the PV technology is significant, producing more than $40 \%$ of the whole electricity demand, while in other four is quite low, below $20 \%$. As a reference, fuel prices in the studied region were 0.88 US $\$ / 1$ in the capital city and 0.96 US $\$ / 1$ in the place of use, in average (September 2010). Future systems should consider the use of biofuel produced from agricultural wastes, if locally available, to fuel the diesel, within other renewable alternatives.

As a consequence of this monitoring and analysis work, a repowering of the PV-battery system has been performed in the three villages with the lowest PV ratio. Additional $1200 \mathrm{Wp}$ have been installed in Misarrumi (id. 8), $600 \mathrm{Wp}$ in Pastos Chicos (id.10) and $800 \mathrm{Wp}$ in Pozo Colorado (id. 11), with first promising results in terms of fuel saving.

In Fig. 11 the system installed at Loma Blanca (id. 7) is analyzed year by year.

In this village, the electricity demand has doubled in a 7 years period, mostly coverd by the diesel generator with a fully used PV subsystem. Then, the system fuel consumption rate has moved from $0.21 / \mathrm{kW}$ h to more than $0.41 / \mathrm{kW} \mathrm{h}$, again referred

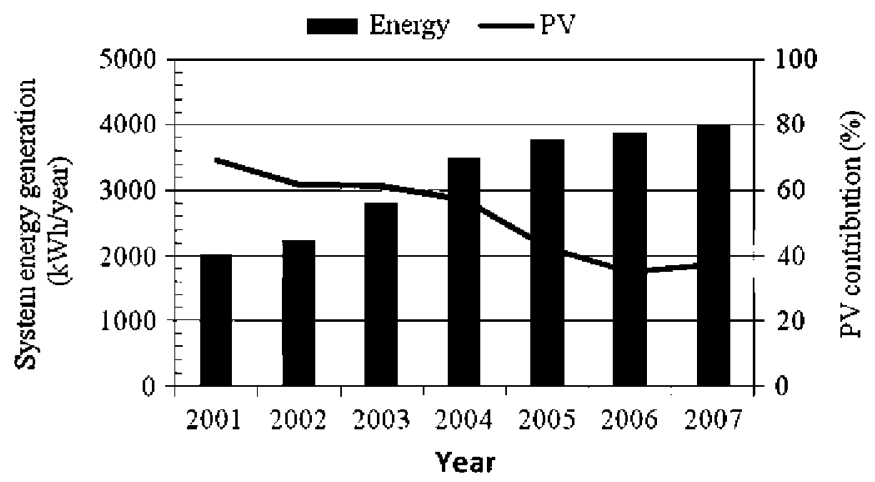

Fig. 11. PV contribution in an electricity demand growth scenario (PV-diesel installation, Loma Blanca, Jujuy, id. 7). to the whole electricity production (PV + diesel). The PV relative contribution has decreased from $70 \%$ to $35 \%$ in the same period, with the hypothesis ofa diesel generator efficiency of $0.7 \mathrm{l} / \mathrm{kW} \mathrm{h}$.

It should be noted that as long as the battery ages, its real capacity decreases due to the different degradation processes, so the fuel consumption rises.

In the field, different influencing factors are mixed into a quite complex performance, from system sizing with quality equipment, through the installation and maintenance tasks, with a certain solar radiation incident and a variable power load demand. Besides, the control strategy applied to collective PV and PV-diesel systems is also a relevant factor although its influence can be only perceived in the medium-term.

\section{Conclusions}

The number of PV and PV-hybrid microgrids installed worldwide has experience a significant increase during the recent years. It is considered a better solution that individual solar home systems for small and medium-size villages (rural but not extremely dispersed population). It has been utilized also for improving the energy service and to reduce maintenance costs of old diesel plants. At this stage, there is still a lot of work to do on quality improvement research. This work tries to contribute to it by analyzing the field operation of twelve isolated microgrids installed in the rural area of the province of Jujuy, Argentina. Seven of them are supplied by hybrid PV-diesel systems and the other five by PV-batteries with no additional support. It has been discussed how the load demand has a significant, but different, influence on both type of systems. While in the villages supplied only by PV arrays the load demand is "auto-regulated" by the own generation and storing capacity, in PV-diesel ones, a load demand increase directly affects the fuel consumption rate. Together with global and mean values, it is interesting to monitor the evolution of each system during a number of years.

The operational settings defined to prevent from deep-battery discharge constitute an essential decision in system design and latter performance. In collective PV systems a balance between daily energy supply and battery lifetime is always a complex issue to deal with. Besides, in PV-diesel installations, battery protection is achieved by increasing fuel expenses. In all cases flexible settings according to system evolution are recommended.

\section{Acknowledgments}

This research and paper has been possible thanks to the support of the Action 708AC0357: Electrificación con Fuentes Renovables a Gran Escala para la Población Rural Latinoamericana (ELECSOLRURAL, 2008-2011), funded by CYTED (Ciencia y Tecnologçía para el Desarrollo).

\section{References}

[1] World energy outlook: Executive summary. International Energy Agency; 2009.

[2] Ilskog E, Kjellström B. And then they lived sustainably ever after?-assessment of rural electrification cases by means of indicators. Energy Policy 2008;36:2674-84.

[3] Chaurey A, Kandpal TC. Assessment and evaluation of PV based decentralized rural electrification: an overview. Renewable and Sustainable Energy Reviews 2010;14:2266-78.

[4] Chaurey A, Kandpal TC. A techno-economic comparison of rural electrification based on solar home systems and PV microgrids. Energy Policy 2010;38:3118-29. 
[5] Klinghammer W, Nörenberg K. Constructing village PV hybrid power systems on a wide - scale in Western China: experience gained. In: 3rd European PVhybrid \& mini-grid conference. Aix en Provence: 2006.

[6] Muñoz J, Narvarte L, Lorenzo E. Experience with PV-diesel hybrid village power systems in Southern Morocco. Progress in Photovolytaics: Research and Applications 2007;15(6):529-39.

[7] Phuangpormpitak N, Kumar S. PV hybrid systemsfor rural electrification in Thailand. Renewable and Sustainable Energy Reviews 2007;11:1530-43.

[8] Schmid AL, Amaral Hoffmann CA. Replacing diesel by solar in the Amazon: short-term economic feasibility of PV-diesel hybrid systems. Energy Policy 2004;32:881-98.

[9] Kaldellis JK, Zafirakis D, Kondili E. Optimum autonomous stand-alone photovoltaic system design on the basis of energy pay-back analysis. Energy 2009;34:1187-98.

[10] Díaz P. Egido MA. Experimental analysis of battery charge regulation in photovoltaic systems. Progress in Photovoltaics: Research and Applications 2003;11(7):481-93.

[11] Cui N, Schmid J, Chen A. Data and performance evaluation of a PV hybrid system in Gambia. In: IEEE 6th international power electronics and motion control conference. 2009. p. 462-465.

[12] Barley CD. Optimal dispatch strategy in remote hybrid power systems. Solar Energy 1996;58(4-6):165-79.

[13] Seeling GC. A combined optimisation concept for the design and operation strategy of hybrid-PV energy system. Solar Energy 1997;61(2):77-87.

[14] Gupta A, Saini RP, Sharma MP. Steady-state modelling of hybrid energy system for off grid electrification of cluster of village. Renewable Energy 2010;35:520-35.

[15] Muselli M, Notton $G$, Louche A. Design of hybrid-photovoltaic power generator, with optimization of energy managemet. Solar Energy 1999;65(3):143-57.

[16] Dufo-López R, Bernal-Agustín JL. Design and control strategies of PV-Diesel systems using genetic algorithm. Solar Energy 2005;79:33-46.

[17] Bernal-Agustín JL, Dufo-López R. Simulation and optimization of stand-alone hybrid renewable energy systems. Renewable and Sustainable Energy Reviews 2009;13:2111-8.
[18] Arun P, Banerjee R, Bandyopadhyay S. Optimum sizing of battery-integrateddiesel generator for remote electrification through design-space approach. Energy 2008;33:1155-68.

[19] Mondal AH, Denich M. Hybrid systems for decentralized power generation in Bangladesh. Energy for Sustainable Development 2010;14:48-55.

[20] Lau KY, Yousof MFM, Arshad SNM, Anwari M, Yatim AHM. Performance analysis of hybrid photovoltaic/diesel energy system under Malaysian conditions. Energy 2010;35:3245-55.

[21] Nfah EM, Ngundamb JM, Tchinda R. Modelling of solar/diesel/battery hybrid power systems for far-north Cameroon. Renewable Energy 2007;32:832-44.

[22] Rehman S, Al-Hadhrami Luai M. Study of a solar PV-diesel-battery hybrid power system for a remotely located population near Rafha, Saudi Arabia. Energy 2010;35:4986-95.

[23] Himri Y, Stambouli AB, Draoui B, Himri S. Techno-economical study of hybrid power system for a remote village in Algeria. Energy 2008;33:1128-36.

[24] Kamel S, Dahl C. The economics of hybrid power systems for sustainable desert agriculture in Egypt. Energy 2005;30:1271-81.

[25] Nandi SK, Ghosh HR. Prospect of wind-PV-battery hybrid power system as an alternative to grid extension in Bangladesh. Energy 2010;35:3040-7.

[26] Abdullah MO, Yung VC, Anyi M, Othman AK, Hamid KB Ab, Tarawe J. Review and comparison study of hybrid diesel/solar/hydro/fuel cell energy schemes for a rural ICT telecenter. Energy 2010;35:639-46.

[27] Hengst S, Luong-Van DM, Everett JR, Lawrence JS, Ashley MCB, Castel D, et al. A small, high-efficiency diesel generator for high-altitude use in Antarctica. International Journal of Energy Research 2010;34(9):827-38.

[28] Wakao S, Nakao K. Reduction of fuel consumption in PV/diesel hybrid power generation system by dynamic programming combined with genetic algorithm. In: IEEE 4th world conference on photovoltaic energy conversion. 2006. p. $2335-2338$.

[29] Papadopoulos DP, Maltas EZ. Design, operation and economic analysis of autonomous hybrid PV-diesel power systems including battery storage. Journal of Electrical Engineering 2010;61(1):3-10.

[30] Díaz P, Arias CA, Peña R, Sandoval D. Far from the grid: a rural electrification field study. Renewable Energy 2010;35:2829-34. 